\title{
Exploring Tacit Knowledge Sharing Enhancer Factors in Non- Profit Organizations Paper
}

\author{
Farhanah Fitria MUSTARI \\ Achmad GHAZALI ${ }^{2}$
}

DOI: $10.24818 / \mathrm{mer} / 2022.02-05$

\begin{abstract}
Non-profit Organizations (NPOs) have a wide range of social missions and impacts. This organization is supported by volunteers and needs to survive amidst competition and move in a sustainable direction. They see the necessity to be involved in the many stages of creating value for an organization. One of the underlying phenomena of value creation is the tacit knowledge-sharing process. However, academic research and scientific publications on tacit knowledge sharing (TKS) in non-profit organizations in Indonesia are still minimal and even rare. This paper aims to explore how tacit knowledge (TK) sharing occurred among volunteers in Non-Profit Organizations and drivers of TK sharing (TKS), including individual and organizational factors. This study explores the abovementioned topics through in-depth interviews with volunteers utilizing open-ended questions to acquire deep insights into the TKS issue. Thematic analysis has been carried out using data coding to extract themes. The findings revealed that various drivers for the smooth transfer of TK have been identified based on individual and organizational elements. These findings will be beneficial to academics and practitioners looking for accurate data on the enabling aspects of TKS based on two factors (individual and organizational). Moreover, the use of knowledge sharing in NPOs would be filling a gap in the literature on the topic.
\end{abstract}

KEYWORDS: tacit knowledge, knowledge sharing, knowledge management, non-profit organizations

JEL CLASSIFICATION: L31, M20, J24, O15

\section{INTRODUCTION}

Realizing that non-profit organizations need to grow over time, the process of flourishing should consider the human element in them. Today, NPOs are breaking away from the traditional passive function and taking on a more active (that of influencers) role in the process. They see the necessity to be involved in the many stages of creating value for an organization. Therefore, the vital role in improving reliability and mutual understanding within an organization is recognized by knowledge sharing. The public and private sectors have dominated research on knowledge sharing. It is possible to refer to the knowledge-sharing work by Shandu et al. (2011) and Zawawi et al. (2011) for public sector organizations. Additionally, Del Giudice et al. (2015) contributed to determining the factors that influence knowledge transfer in two different companies in private sector organizations. Because knowledge sharing has many potential benefits, many organizations have devoted a significant amount of time and money to knowledge management.

However, most of the research in knowledge sharing mainly focuses on the employee sector rather than volunteering or social workers in the non-profit organization. In the works, details of

\footnotetext{
${ }^{1}$ School of Business \& Management, Bandung Institute of Technology, Indonesia, farhanah.fitria@sbm-itb.ac.id

${ }^{2}$ School of Business \& Management, Bandung Institute of Technology, Indonesia, achmadghazali@sbm-itb.ac.id
} 
research on knowledge sharing for the third sector, especially non-profits, are discussed by several authors such as: Oliveira and Pinheiro (2020) and Rathi et al. (2014). Whereas, according to Gavurová et al. (2019), non-profit organizations (NPOs) play a crucial role in the knowledge management process, particularly when it comes to reaching the most disadvantaged social groups. In addition, knowledge sharing opens up new avenues for environmental nongovernmental organizations (NGOs) to achieve long-term development goals. Environmental non-profits will benefit from this innovation in adaptability and flexibility (Masuda et al., 2018). To conduct this research, we found that the literature on knowledge sharing in organizations mainly focused on shared knowledge, but did not consider why non-profit organizations might enhance people's intention to share and sustain mutual understanding.

Knowledge may be classified into two sorts based on how much it can be structured and codified. For Nonaka (1994), explicit knowledge is codified. It can be easily communicated, transferred, and presented in manuals, plans, procedures, etc. Tacit knowledge is implicit, semiconscious, and unconscious knowledge held in people's heads (Leonard \& Sensiper, 1998). Nonaka and Krogh (2009) explained that the process is characterized as "learning by doing." This paper focuses on tacit knowledge, which is difficult to explain since embedded inhabits, procedures, and routines (Beckmann, 2009). Referring to Small and Sage (2005), tacit knowledge sharing is highly beneficial, since it increases organizational productivity. For non-profit organizations, tacit knowledge is a valuable resource that allows them to act in complex and unpredictable situations. However, such information is frequently only known by volunteers. Consequently, if that volunteer leaves the organization without sharing the knowledge and another volunteer replaces them, it will eliminate the organization's competitive advantage. According to Joia and Lemos (2010), it must be shared across the organization for tacit knowledge to become an adequate basis of long-term competitive advantage. The current research focuses on determining the prevalence of indicators for unspoken knowledge exchange among volunteers in Non-Profit Organizations based in Bandung City, Indonesia. This paper summarizes the objectives, literature review, research methodology, findings \& discussion, study limitations, and research novelty or significance. Here is a brief overview of the topic and critical terms. First, the concepts of knowledge sharing and the elements that influence NPOs' willingness to share knowledge are defined in a theoretical framework, with a focus on the role of the volunteer. The results will be presented and discussed in the next section. Finally, we offer our findings and suggestions for future research.

\section{LITERATURE REVIEW}

Several researchers have been contributing to understanding the impact of tacit knowledge, such as Ganguly et al. (2019) on understanding the role of tacit knowledge sharing in building an organization's innovative capability; Huie et al. (2020) investigated the impact of tacit knowledge sharing on job performance; Cai et al. (2020) found that employee vigour acted as a psychological mechanism that mediates the effect of social capital on tacit knowledgesharing intention; and Perumal and Sreekumaran (2021) about employee's perception towards tacit knowledge sharing (TKS). Because of the nature of Tacit Knowledge and its accumulation over time, communicating it between volunteers and employees in any organization is always tricky. Tacit knowledge is occasionally lost in organizations due to volunteer and employee turnover or project completion. As previously said, these organizations can continue to exist and provide more benefits if they can figure out how to manage their tacit knowledge. Therefore, to better understand how tacit knowledge sharing works, we must analyze indicators into elements and typologies. 


\subsection{Indicators of tacit knowledge sharing: individual aspect}

The willingness and capacity of individuals to share what they know and use what they learn is critical to both formal and informal tacit knowledge transmission. As a result, it is vital to understand the specific characteristics that drive people to share their knowledge.

Time Management on an Individual Level - Individual time management has emerged as a critical predictor of tacit knowledge sharing. As previously explained, tacit knowledge is the direct product of experience, thought, and dialogue - three time-consuming tasks. As a result, the first indicator of tacit knowledge sharing aims to demonstrate whether workers have enough time to communicate tacit information within the organization (Castellani, 2019).

Altruism \& Other-Oriented Behavior - Some individuals tend to share their knowledge without asking for anything in return. According to the literature, individuals working in the public and non-profit sectors have more excellent altruistic reasons, such as serving the public and assisting the underprivileged, than for-profit workers (Chen \& Lee, 2014). Moreover, by understanding them, managers can respond by allocating particular roles to generous people within teams, assigning them activities to cooperate and engaging in socialization with other people. Such decisions may improve group knowledge sharing (Obrenovic, B, 2020). It is in line with research conducted by Burns (2006), Briggs (2010), and Carpenter and Myers (2010) regarding the effect of altruism (other-oriented attitude) on volunteer motivation in non-profit organizations.

Social Ties \& Trust - Nonaka and Takeuchi (1995) demonstrated that as individuals get closer in their relationships, they become more motivated to act in ways that benefit the other (Holste \& Dail, 2010). Moreover, the lower the risks and uncertainties in tacit knowledge sharing, the stronger the trust between the organization's members. Building a trusted network is dependent on shared social and cultural norms, as well as mutual expectations.

\subsection{Indicators of tacit knowledge sharing - organizational aspect}

In this case, we will look at the role of management support and the relationship between volunteer members interacting with each other in non-profit organizations.

Management Support (Mentoring) - Previous research has found that management support is an organizational factor that influences knowledge sharing (Han \& Anantatmula, 2008; Seba et al., 2012). By using a mentoring approach, mentor programs provide more personalized knowledge sharing and allow experienced volunteers/senior employees to transmit their experience directly. Most of all, in non-profit organizations, mentoring is often done informally. However, it can be more effective when organized, allowing for a more equitable distribution of mentoring opportunities and enabling organizational guidance in the knowledge exchange process (Mayfield, 2010).

Management Support (Recognition and Reward) - Support can come in praise, recognition, performance appraisals that include knowledge-sharing behaviors or motivating goals. Organizations should recognize and appreciate their volunteers to encourage them to share their knowledge and experience. Saifi et al. (2016) have recently shown that top and middle management can play an essential role in promoting knowledge sharing, such as 
encouraging participation in decision-making, providing recognition, encouraging formal and informal communication, putting knowledge into practice, and creating positive movement.

\section{METHODOLOGY}

The purpose of this study was to explore the elements that encourage tacit knowledge sharing among volunteers in non-profit organizations. This study employed a qualitative research method to explore Tacit Knowledge Sharing volunteer experiences. Qualitative research is typically unstructured, exploratory, and focuses on understanding and acquiring insights. To provide a more accurate and clear understanding of the interviewee's position in an unrestricted context, in-depth structured interviews were undertaken to ask a series of openended questions to find enablers and impediments to tacit knowledge sharing (TKS). Furthermore, respondents are directed to explore how collaboration and skill-sharing occur when volunteering rather than directly discussing knowledge management and knowledge sharing. Before the interview, the participants provided written consent, and the goal of the research was explained to guarantee ethical concerns. Several questions were asked during the interview, but only three questions relevant to the topic were examined for this paper:

1. Respondents were asked about how TKS occurred in their organization.

2. TKS or transmission drivers were investigated.

3. The importance, value, and benefit of contributing to TKS.

The ideal interviewee profile for the interviews was a volunteer from each program batch, resulting in a stratified purposeful sample. The criteria for volunteers recommended by the organization are those who complete the program period to completion and those who continue to participate for more than six months. In qualitative research, sample sizes should not be too large, extracting thick and rich data (Onwuegbuzie \& Leech, 2007). This study aims to provide understanding, develop explanations, and generate ideas rather than estimate the prevalence of a phenomenon or make generalizations. Only a limited number of respondents were required. The sample size $(n=8)$ was also justified because the interviewees possessed 'information power.' The more information the sample has, the fewer interviewers are needed.

Table 1. Demographic profile of the informants

\begin{tabular}{|c|c|c|c|}
\hline Participant & $\begin{array}{c}\text { Volunteering } \\
\text { Duration }\end{array}$ & $\begin{array}{c}\text { Volunteering Entry } \\
\text { Year }\end{array}$ & Current Profession \\
\hline IK & 12 Months & 2018 & Private Sector Employee \\
\hline RW & 4 Months & 2018 & Engineering \\
\hline MR & 12 Months & 2019 & Trainer \\
\hline NS & 5 Months & 2019 & State-Owned Employee \\
\hline WN & 4 Months & 2019 & State-Owned Employee \\
\hline TI & 5 Months & 2018 & Start-up Employee \\
\hline WD & 4 Months & 2019 & Private Sector Employee \\
\hline SL & 4 Months & 2019 & Academic Assistant \\
\hline DD & 6 Months & 2020 & Non-Profit Organization \\
& & & Staff \\
\hline
\end{tabular}

Source: data processed by the authors

The data were analyzed using an inductive technique. Thematic analysis (Braun \& Clarke, 2006) was employed in the study to qualitatively analyze interview transcriptions. Thematic 
analysis is flexible, and researchers can use theory or any theoretical framework. According to Maguire and Delahunt (2017), the thematic analysis consists of six critical analyzing transcribed data. The initial stage is to read and re-read transcriptions to become acquainted with the facts. It allows researchers to develop themes or initial codes for interview data based on the interview guide. The interview guide also aids researchers in developing the initial coding framework, as it is based on the study topic, the researcher's personal experience, and published literature (King et al., 2004). The data are reported using a structured interpretative technique that draws interpretative examples from the interview transcripts. The coding system helps to organize the data in a way that is understandable. As a result of the coding system, exciting and noteworthy patterns in the data are recognized. The researcher reviewed the themes to extract as much information as possible from the data.

\section{RESULTS}

The study extracted various themes, and subthemes of the TK phenomenon, drivers of transmission or sharing in a non-profit organization, and value is given to new ideas and innovation.

Table 2. Summary of Thematic Analysis

\begin{tabular}{|c|c|c|}
\hline $\begin{array}{l}\text { Research } \\
\text { Questions }\end{array}$ & Main Theme & Sub-Theme \\
\hline \multirow{3}{*}{$\begin{array}{l}\text { How TKS occurred } \\
\text { in Non-Profit } \\
\text { Organization? }\end{array}$} & $\begin{array}{l}\text { - Mentorship/Face-to-Face } \\
\text { Learning }\end{array}$ & $\begin{array}{ll}\text { - } & \text { Learning Evaluation } \\
\text { - } & \text { Performance Feedback } \\
\text { - } & \text { Learning by Modelling }\end{array}$ \\
\hline & $\begin{array}{l}\text { Routine Sharing of } \\
\text { Knowledge and Experience }\end{array}$ & $\begin{array}{ll}\text { - } & \text { Weekly Preparation } \\
& \text { Meeting } \\
\text { - } & \text { Socialization } \\
\text { - } & \text { Direct Conversation } \\
\text { - } & \text { Simulation } \\
\end{array}$ \\
\hline & - Exploration & $\begin{array}{ll}- & \text { Experiment New Roles } \\
\text { - } & \text { Engaging with New } \\
& \text { Challenges } \\
\end{array}$ \\
\hline \multirow{2}{*}{$\begin{array}{l}\text { Drivers Factors of } \\
\text { TKS in Non-Profit } \\
\text { Organization? }\end{array}$} & - Individual Drivers & $\begin{array}{ll}\text { - } & \text { Personal Time } \\
& \text { Management } \\
\text { - } & \text { Social Bonding } \\
\text { - } & \text { Self-Disclosure } \\
\text { - } & \text { Empathic Behaviour } \\
\end{array}$ \\
\hline & - Organization Drivers & $\begin{array}{ll}\text { - } & \text { Appreciative Culture } \\
\text { - } & \text { Personal } \\
& \text { Guidance/Mentorship } \\
\text { - } & \text { Learning Opportunity }\end{array}$ \\
\hline
\end{tabular}

Source: data processed by the authors

How tacit knowledge sharing occurred in non-profit organizations?

The informants shared the TKS phenomenon in non-profit organizations where they taught young orphans at the Orphanage. They reported that TK was distributed by the organization to them and their role in sharing TK to the subject of empowerment. Many resource persons realized that during their time as volunteers, the management team of the organization provided more insight into the wisdom and ways to become an empathic educator. On the one hand, they are also expected to provide knowledge, share experiences, and teach the value of 
kindness gained from the management team in the organization. Thus, the TK obtained by participants mainly came from story-telling, experience in the field, and mentoring. One of the informants said that while being a mentor, the TKS process was shared from heart to heart and was often difficult to describe in words. Consciously, the participants learned by observing the examples applied by the management team.

On the other hand, they also stated that they received positive lessons to be totally and fully committed. All participants acknowledged that the initial and weekly educational program before the activity further matured the concept of the material syllabus and a means to TKS. It was conceded by Participant NS, who considered that weekly briefings played an essential role in preparing herself before the activity but also trained her brainstorming skills and gained additional insights from senior volunteers. Not much different, one of the participants also considers a simulation session in the weekly briefing that further strengthens her experience and knowledge.

The TKS process also runs when they are challenged to get used to getting out of their comfort zone by experimenting with different roles in each teaching meeting. As stated by Participant SL, during his time as a teaching volunteer, he has experienced three different roles. The experience in the field gave him more opportunities to learn new things. However, the management team did not hesitate to teach the volunteers precisely without hindering their exploration abilities. Not only that, exploring new challenges and roles is part of learning by doing. Thus, the flow of the non-profit organization's method for conducting TKS started with socialization at the beginning of the program, followed by weekly briefings before the teaching activity, inserting personal guidance/mentoring, and continuing to share knowledge and wisdom experiences with subject of empowerment.

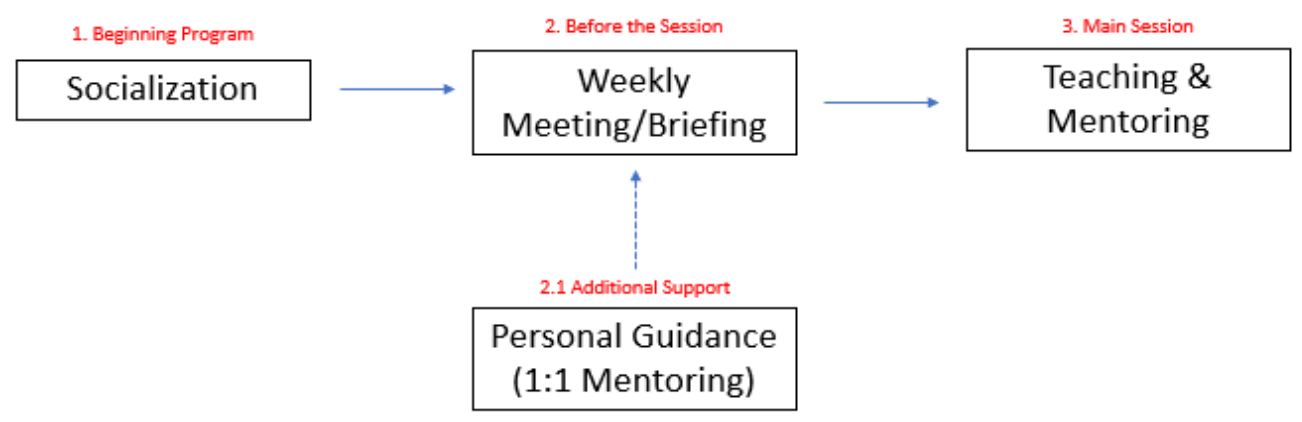

Figure 1. TKS Method in Case Study

Source: data processed by the authors

What are the individual \& organizational drivers of tacit knowledge sharing specific to nonprofit organizations?

The participants mentioned various drivers of effective and improved TK transmission based on individual and organizational perspectives. Many participants noted that the frequency of meetings between the management team, volunteers, and their mentees at the Orphanage determines the depth of knowledge and experience that can be shared. Participants also felt that it was not difficult to take the time to share tacit knowledge with mentees at the Orphanage if the schedule had been determined/prepared. For example, it is done every weekend. However, they admit that sharing tacit knowledge such as experiences and wisdom 
needs to be prioritized, which matters are relevant to the intended subject. They also emphasized the management team's relationship and volunteered with their mentees in the Orphanage. TK transmission will be smooth and effective if both people are closely associated. Participant IK, Participant TI, Participant RW, and Participant MR emphasized the importance of being open to each other (self-disclosure) and being yourself (authentic). For example, self-introduction to each other will make it easier for relationships to be closer. There is no distance between them. They are also associated with social ties with aspects of trust, especially in tacit knowledge sharing. Aiming that knowledge can be conveyed maximally to recipients, trust is the basic foundation for non-profit organizations toward volunteers and volunteers to mentees at the Orphanage. In addition, several participants mentioned the importance of appreciation and physical touch as a sign of empowerment to improve the quality of trust with mentees at the Orphanage. They believe that TKS will be more internalized into their lives with trust. Not only that, trust is built by perspective-taking with one's condition. Participant SL emphasizes that empathetic behavior makes her mentoring group get closer.

The process of tacit knowledge sharing that occurs when volunteering gives an impression and impact on participants' lives. Starting from the essence of the material taught to the mentees at the Orphanage related to soft skills, they continued with the experience of being a mentor until the emotional rewards that they got from the activities. Participant IK emphasized that after becoming a volunteer, she got three life lessons that she implemented:

- The importance of empathy in relationships.

- The essence of sharing is not just material.

- The feeling of happiness when sharing knowledge and experiences with others.

Participant MR also realized that the value brought from the process of TKS is about selfacceptance. This wisdom was obtained when she received positive feedback from mentoring activities from the management team and lessons that were always socialized in each briefing meeting. Suppose that the internalized values in the participants are more related to kindness and compassion. On the other hand, the participants acknowledged that the TKS process trained their soft skills, which they rarely realized before.

In addition, the trust that is built on a solid foundation makes them not reluctant to share more. That means participants realize that sharing knowledge and experiences with others is no doubt. Instead, it is an embodiment of selfless kindness (altruism). In building trust, it is essential to appreciate the development of a more bonded relationship. It can be seen from the organizational side as a driving force for tacit knowledge sharing. Most participants realized that a mutually supportive organizational culture could encourage them to share tacit knowledge with mentees outside the volunteer's role. Participant WD mentioned that being recognized for her presence and process drove her to be more actively engaged in tacit knowledge sharing.

Moreover, personal support from mentoring activities is to provide evaluation and give more insight, especially the application of wisdom in daily life. This was stated by Participant MR that recognizing this organizational activity made her more reflective on the process she did as a volunteer, as well as future improvement strategies. It was also acknowledged by Participant SL, who illustrated that organizational support through mentoring had a significant impact on changing herself to become a better version. Participants also emphasized the opportunity to learn new roles in teaching that could improve their soft skills supported by the organizations, which made them eager to share knowledge. Participant NS 
stated that another driver motivates her to share the knowledge and positive experiences with the mentees at the Orphanage. Besides seeing positive outcomes from her mentees, exposure to maximize the self-potential. Therefore, management support, such as an appreciative culture, personal guidance, and direction to learning more challenges in teaching methods, becomes an enhancer from the organizational side.

What are the given values and benefits of tacit knowledge sharing by being a volunteer in non-profit organizations?

The process of tacit knowledge sharing that occurs when volunteering gives an impression and impact on participants' lives. Starting from the essence of the material taught to the mentees at the Orphanage related to soft skills, they continued with the experience of being a mentor until the emotional rewards that they got from the activities. Participant IK emphasized that after becoming a volunteer, she got three life lessons that she implemented. First, the importance of empathy in relationships. Second, the essence of sharing is not just material. The last is the feeling of happiness when sharing knowledge and experiences with others. Participant MR also realized that the value brought from the process of TKS is about self-acceptance. This wisdom was obtained when she received positive feedback from the mentoring activities from the management team and lessons that were always socialized at each briefing meeting. Suppose that the internalized values in the participants are more related to kindness and compassion. On the other hand, the participants acknowledged that the TKS process trained their soft skills, which they rarely realized before.

\section{DISCUSSION}

According to Teegen et al. (2004), people inside NPOs are people-driven. They involve taskoriented groups with similar interests, frequently reflecting humanitarian or community-level activities. Non-profit organizations (NPOs) focus on activities that add social value to society and can be classified as knowledge-intensive units. As explained in the discussion section, volunteers involved in non-profit organizations gain knowledge and experience from the organization and how they can pass on to empowering and including the people around them. Therefore, within NPO, the knowledge is created and circulates through four distinct cycles (Lettieri et al., 2004). The first cycle is concerned with an individual level, followed by the second cycle, which incorporates activities of transfer/sharing from the individual level to the group level. The third cycle makes the knowledge available to the entire organization. The final cycle is an integration phase in which the organizations share with larger communities. In other words, understanding what to share, how to share it, and when to share it can be learned. However, the abilities do not get very far in the absence of opportunity. Knowledgesharing opportunities arise from both direct and indirect experience, such as trial-and-error learning, observational learning, or informal networks.

During the meeting process, there were activities to share knowledge and experiences carried out by volunteers with the organization's management team. Referring to Hawryszkiewycz and Lin (2003), "meetings are only effective if it follows methods that foster idea development appraisal, and discussion while adhering to well-defined learning steps." Moreover, the TKS method is limited to mentoring and direct meetings and observing behavior, conversing, and storytelling until learning by doing. When discussing the factors that drive TKS behavior, individual elements are also essential because tacit knowledge is directly linked to a person's experiences, thoughts, and beliefs. According to Nonaka and Tekeuchi (1995), knowledge sharing will not be successful within an organization unless humans are involved (Ramirez et al, 2011). For example, behavior that reflects some 
individuals may share their experience and knowledge with others without thinking of the benefit they may gain from it. In another sense, giving out something without expecting any return is an altruistic behavior that is part of individual drivers. Social capital is an attitude that includes reciprocity, links, shared values, and language. Altruistic people naturally tend to rely on social capital components in their interactions. Thus, individuals inside an organization can freely share their knowledge without regard for any strings attached (Okyere-Kwakye \& Nor, 2011). Another driving factor for individuals to share knowledge is the element of mutual trust. Therefore, to support mutual trust, a positive communication environment is needed. Communication climate refers to the behavioral characteristics of a work environment, such as trust in knowledge being transmitted throughout the organization (Guzley, 1992). Listening, persuading, teaching, learning, presenting, cooperating, and coordinating are components of communication as one of the five competencies in organizations, according to (Davenport et al., 2001). As a result, most people are unwilling to offer their knowledge and expertise unless they trust the person in front of them. They must trust that people will not mistreat their knowledge. They must trust that the knowledge gained is valid and reliable because of the source of information (Bratianu \& Orzea, 2010).

From an individual perspective, TKS is also driven by social bonds between individuals as a manifestation of mutual trust. Borges et al. (2019) stated that the social ties between the knowledge source and the knowledge recipient are crucial factors in the desire for tacit knowledge sharing. Small and Sage (2006) predicted that good social ties and a positive organizational culture could lead to knowledge-sharing. The use of encouragement, stimulation, or any reward can help change the organizational culture to one that values knowledge sharing. Organizations that enforce values promoting engagement in knowledge sharing are more likely to accomplish greater levels of success in knowledge sharing (Jalal et al., 2010). Creating an organizational culture that prioritizes interpersonal connection, rewards and recognizes it, and views people as valuable assets to develop can boost knowledge exchange inside the organization. In addition, organizational support that makes knowledge sharing a learning opportunity encourages volunteers or individuals in non-profit organizations to do TKS both for internal and external parties. As a result, tactics for engaging volunteers in the process of reflection, articulation, and investigation of experience have been devised in the hopes of facilitating learning. Action learning, mentorship, coaching, and communities of practice are a few examples.

\subsection{Managerial implications}

This study explores the factors influencing TKS in non-profit organizations centered on community service. This study focuses on the individual as a member of a group and an organization and knowledge characteristics. Knowledge generation, retention, and transfer are referred to as "knowledge sharing." Furthermore, the tacit knowledge-sharing strategy helped volunteers to realize their desire to share their expertise, foster their capacity to learn, and allow the organization's values to be transmitted to the community through the volunteers. Not only on the volunteer side, but it may also support management teams in non-profit organizations by identifying methods of maintaining and encouraging volunteers to get the best results out of them. Some significant emphasis, such as mentoring \& dialogue activities, guides the volunteers and transfers wisdom/insight, which becomes a positive value for their lives. Therefore, management must strengthen teamwork, shared vision, and mutuality of goals among organizational members to achieve these goals. Additionally, the findings can guide managers to improve the smooth transfer of knowledge, competence, and experience.

\section{CONCLUCION \& FUTURE RESEARCH}


This research paper explores several aspects of tacit knowledge sharing in volunteering work and highlights two essential criteria that drive knowledge sharing within organizations. This study addresses the factors for knowledge sharing, but it also proposes remedies based on interviews with volunteers from the same organization. Considering the study's result, the two main factors influencing Tacit Knowledge Sharing in Non-Profit Organizations (NPOs) are the individual and management sides. It is not much different from for-profit organizations (FPOs), which look at it from the individual and management perspectives. The extent to which empirical findings may be extrapolated is limited. More research should understand how knowledge practices connect to knowledge generation processes during volunteering or social work. A multi-case study in various Non-Profit Organizations could help to broaden the generalization of the findings. Future work suggests that research analyzes the effect of this tacit knowledge sharing on volunteer engagement and organizational performance, particularly fulfilling the organization's mission.

Furthermore, the research should be conducted for various types of organizations. Different organizations have varied qualities, and information sharing will have different implications. Finally, the authors expect that their analysis has contributed to a better understanding of the phenomenon of tacit knowledge sharing within organizations.

\section{ACKNOWLEDGEMENTS}

The authors wish to thank the School of Business and Management (Faculty) and Institute of Technology Bandung (Host University) for supporting the research paper. In particular, the Teman Saling Berbagi Foundation has already provided the opportunity to be the case study in this research.

\section{REFERENCES}

Beckmann, S. (2009). Drivers for knowledge sharing: Propositions for the role of motivational differences. International Journal of Strategic Change Management, 1, 239-249.

Bolisani, E., \& Bratianu, C. (2018). The emergence of knowledge management. Emergent knowledge strategies, 23-47.

Borges, R., Bernardi, M., \& Petrin, R. (2019). Cross-country findings on tacit knowledge sharing: Evidence from the Brazilian and Indonesian IT workers. Journal of Knowledge Management, 23(4), 742-762.

Braun, V., \& Clarke, V. (2006). Using thematic analysis in psychology, Qualitative Research in Psychology, 3(2), 77-101.

Briggs, E., Peterson, M., \& Gregory, G. (2010). Toward a Better Understanding of Volunteering for Nonprofit Organizations: Explaining Volunteers' Pro-Social Attitudes. Journal of Macromarketing, 30(1), 61-76.

Bratianu, C., \& Orzea, I. (2010). Tacit knowledge sharing in organizational knowledge dynamics. Proceedings of the 2nd European Conference on Intellectual Capital, 107-1114.

Burns, D.J., Reid, J.S., Toncar, M. et al. (2006). Motivations to volunteer: The role of altruism. International Review on Public and Nonprofit Marketing, 3, 79-91.

Cai, Y., Song, Y., Xiao, X., \& Shi, W. (2020). The effect of social capital on tacit knowledgesharing intention: The mediating role of employee vigor. Sage Open, 10(3). 
Castellani, P., Rossato, C., \& Giareta, E. (2019). Tacit knowledge sharing in knowledgeintensive firms: the perceptions of team members and team leaders. Review of Managerial Science, 125-155.

Carpenter, J., \& Myers, C. K. (2010). Why volunteer? Evidence on the role of altruism, image, and incentives. Journal of Public Economics, 94(11-12), 911-920.

Chen, C.-A., \& Lee, Y. (2014). A Closer Look at the Difference Between Public and Nonprofit Employees' Volunteering. International Public Management Journal, 18(1), 108-129.

Davenport, T.H., \& Grover V. (2001). General Perspectives on Knowledge Management : Fostering a Research Agenda. Journal of Management Information Systems, 18, 5-21.

Del Giudice, M., Della Peruta, M.R., \& Maggioni, V. (2015). A model for the diffusion of knowledge sharing technologies inside private transport companies. Journal of Knowledge Management, 19(3), 611-625.

Eugene O.K., Khalil M.N., \& Khairiah S.Z. (2019). Intergroup Contact Theory: Examining Knowledge Sharing Among Individuals From Different Tribes. International Journal of Knowledge Management, 15, 81-96.

Ganguly, A., Talukdar, A., \& Chatterjee, D. (2019). Evaluating the role of social capital, tacit knowledge sharing, knowledge quality and reciprocity in determining innovation capability of an organization. Journal of Knowledge Management, 23 (6), 1105-1135.

Gavurová, B., Tuček, D., \& Kováč, V. (2019). Economic aspects of public procurement parameters in the tertiary education sector. Administratie si Management Public, 32, 42-62.

Guzley, R.M. 1992. Organizational climate and communication climate: Predictors of commitment to the organization. Management Communication Quarterly, 5, 379-402.

Han, B.M., \& Anantatmula, V.S. (2007). Knowledge sharing in large IT organizations: A case study. VINE, 37(4), 421-439.

Hawryszkiewycz, I.T., \& Lin, A. (2003). Process Knowledge Support for Emergent Processes", Proceedings of the $2^{\text {nd }}$ IASTED International Conference on Information and Knowledge Management. Scottsdale, Arizona.

Huie, C.P., Cassaberry, T., \& Rivera, A.K. (2020). The Impact of Tacit Knowledge Sharing on Job Performance. International Journal on Social and Education Sciences, 2(1), $34-40$.

Holste, J., \& Fields, D. (2010). Trust and tacit knowledge sharing and use. Journal of Knowledge Management, 14, 128-140.

Jalal, H.A., Toulson, P., \& Tweed, D. (2010). Organisational cultural values for successful knowledge sharing: the case of Malaysia. Proceedings of the International Conference on Intellectual Capital, Knowledge Management, \& Organizational Learning. The Hong Kong Polytechnic University, Hong Kong.

Joia, L.A., \& Lemos, B. (2010). Relevant factors for tacit knowledge transfer within organizations. Journal of Knowledge Management, 14(3), 410-427.

King, N., Cassell, C., \& Symon, G. (2004). Using templates in the thematic analysis of text. Essential Guide to Qualitative Methods in Organisational Research, 2(1), 256-270.

Leonard, D. \& Sensiper, S. (1998). The role of tacit knowledge in group innovation. California management review, 40(3), 112-132.

Lettieri, E., Borga, F., \& Savoldelli, A. (2004). Knowledge management in non-profit organizations. Journal of Knowledge Management, 8(6), 16-30.

Masuda, Y.J., Liu, Y., Reddy, S.M., Frank, K.A., Burford, K., Fisher, J.R. et al. (2018). Innovation diffusion within large environmental NGOs through informal network agents. Nature Sustainability, 1(4), 190-197. 
Maguire, M., \& Delahunt, B. (2017). Doing a thematic analysis: a practical, step-by-step guide for learning and teaching scholars. The All Ireland Journal of Teaching and Learning in Higher Education, 9(3), 3351-3365.

Milton, M. (2010). Tacit knowledge sharing: techniques for putting a powerful tool in practice. Development and Learning in Organizations: An International Journal, 24 (1), 24-26.

Nonaka, I. (1994). A dynamic theory of organizational knowledge creation. Organization Science, 5(1), 14-37.

Nonaka, I., \& Von Krogh, G. (2009). Perspective-Tacit knowledge and knowledge conversion: Controversy and advancement in organizational knowledge creation theory. Organization Science, 20, 635-652.

Obrenovic, B., Jianguo, D., Tsoy, D., Obrenovic, S., Khan, M.A.S., \& Anwar, F. (2020). The enjoyment of knowledge sharing: Impact of altruism on tacit knowledge-sharing behavior. Frontiers in Psychology, 11, 1496.

Onwuegbuzie, A.J., \& Leech, N.L. (2007). Sampling Designs in Qualitative Research: Making the Sampling Process More Public. The Qualitative Report, 12(2), 238-254.

Oliveira, M., \& Pinheiro, P. (2021). Factors and Barriers to Tacit Knowledge Sharing in Non-Profit Organizations - a Case Study of Volunteer Firefighters in Portugal. Journal of the Knowledge Economy, 12.

Perumal, S., \& Sreekumaran Nair, S. (2021). Impact of views about knowledge and workplace relationships on tacit knowledge sharing. Knowledge Management Research \& Practice, 1-12.

Rathi, D., Given, L., \& Forcier, E. (2014). Interorganisational partnerships and knowledge sharing: The perspective of non-profit organisations (NPOs). Journal of Knowledge Management, 18(5), 867-885.

Ramírez, M.A., Morales, G.J.V., \& Rojas, M.R. (2011). Knowledge Creation, Organizational Learning and Their Effects on Organizational Performance. Inžineriné EkonomikaEngineering Economics, 22, 309-318.

Saifi,S., Dillon, S., \& Mcqueen, R. (2016). The Relationship between Management Support and Knowledge Sharing: An Exploratory Study of Manufacturing Firms. Knowledge and Process Management, 23, 124-135.

Seba, I., Rowley, J., \& Delbridge, R. (2012). Knowledge sharing in the Dubai police force. Journal of Knowledge Management, 16(1), 114-128.

Singh S.M., Kishore, J.K., \& Umi, K.B.I. (2011). Knowledge sharing among public sector employees: evidence from Malaysia. International Journal of Public Sector Management, 24 (3), 206-226.

Small, C. T., \& Sage, A. P. (2005). Knowledge management and knowledge sharing: a review. Information Knowledge Systems Management, 5, 153-169.

Song, D. (2019). The tacit knowledge-sharing strategy analysis in the project work. International Business Research, 2, 83-85.

Teegen, H., Doh, J.P., \& Vachani, S. (2004). The Importance of Nongovernmental Organization (NGOs) in Global Governance and Value Creation: An International Business Research Agenda. Journal of International Business Studies, 35, 463-483.

Zawawi, A.A., Zakaria, Z., Kamarunzaman, N.Z., Noordin, N., Sawal, M.Z.H.M., Junos, N.M. et al. (2011). The study of barrier factors in knowledge sharing: A case study in public university. Management Science and Engineering, 5(1), 59-70.

Zbuchea, A., Ivan, L., Petropoulos, S., \& Pinzaru, F. (2020). Knowledge sharing in NGOs: the importance of the human dimension. Kybernetes, 49 (1), 182-199. 